\title{
EFFECTIVENESS OF GUTTAPERCHA/BIOCERAMIC SEALER REMOVAL DURING RETREATMENT USING DIFFERENT IRRIGATION PROTOCOLS
}

\author{
Nehal Nabil Roshdy* and Adel AbdelWahed**
}

\begin{abstract}
Objectives: The purpose of the study was to assess the amount of residual root canal filling materials (Guttapercha/Bioceramic sealer) after using different irrigation protocols.

Methodology: FortyMandibular premolar teeth were mechanically instrumented using Protaper Next rotary system and obturated with guttapercha master cones (size 25, 0.06 taper) coated with Sure Seal bioceramic sealer (Sure Dent Corp., Gyeonggi-do, Korea). All specimens were incubated for 4 weeks then retreatment was performed using Protaper Universal retreatment system. The specimens were randomly divided into four equal groups $(n=10)$ according to the final irrigation protocol as follow; Conventional needle irrigation, Endovac, UltraX, Passive ultrasonic irrigation. Roots were grooved buccolingualy into two halves. A digital camera connected to the stereomicroscope captured images to each half. The root canals were segmented into thirds (Apical, middle and coronal). Image-J softwarewas used to evaluate and measure the areas with the remaining filling material in each third. Data were analysed using One-way ANOVA followed by Tukey's post hoc test for intergroup comparisons while One-way repeated measures ANOVA was used for intra group comparisons.
\end{abstract}

Results: All groups showed residual filling material in the root canals. The amount of the residual filling materials was significantly reduced upon using passive ultrasonic irrigation $(\mathrm{P}<0.001)$.

Conclusion: None of the irrigant activation methods was capable of completely removing the root canal filling material. Passive Ultrasonic irrigation enhanced the retreatment procedure of root canals previously obturated with gutta percha/bioceramic sealer.

KEYWORDS: Bioceramic Sealer, EndoVac, Passive ultrasonic irrigation, Retreatment, UltraX.

\footnotetext{
* Associate Professor of Endodontics, Faculty of Dentistry, Cairo University

** Endodontic Department- Faculty of Oral and Dental Medicine, Future University
} 


\section{INTRODUCTION}

Non-surgical retreatment procedure aims at removing the existing root canal filling materials and enabling effective chemomechanical preparation, followed by 3-dimensional obturation of the root canal system ${ }^{1}$. The most commonly used core filling material is guttapercha. Its major disadvantages are the lack of adhesion and shrinkage on cooling ${ }^{2}$. That's why it is recommended to use sealer in conjunction with the guttapercha. Sure Seal (Sure Dent Corp., Gyeonggi-do, Korea) is a recently introduced bioceramic sealer. This sealer is biocompatible, osteogenic and provides improved sealing ability to the dentin of the root canal ${ }^{3}$. However, the enhanced sealing ability together with being hard upon setting leads to difficulty in removal in cases when retreatment is required ${ }^{4}$.

Variablemethods have been used to achieve proper retreatment i.e: Solvents, hand files, Nickeltitanium (NiTi) rotary systemsor combination of these techniques ${ }^{5,6}$. Though, rotary NiT'i systems showed high efficiency innon-surgical retreatment procedures ${ }^{7}$, Micro-CT studies revealed failure of any of the retreatment techniques to completely remove obturation materials from the root canal system ${ }^{8}$. Thereby, it becomes essential to identify an irrigantactivation mechanism which could efficiently aid in the removal of the gutta percha/ bioceramic sealer obturation materials from the root canal space.

EndoVac System (Discus Dental, Culver City, CA) was presented to the market as a device that safely delivers the irritant to the apical part of the root canal. It comprises a delivery/ evacuation tip connected to an irrigant syringe and to the highvolume suction of the dental unit. Through a system of a macro/ microcannula connected to the suction, the irrigant present in the pulp chamber is drew by negative pressure to the cannula and eliminated via the suction hose ${ }^{9}$.

UltraX (Eighteenth, Orikam) is a cordless ultrasonic irrigation device that oscillates at 45,000
$\mathrm{kHz}$ utilize ing the acoustic microstreaming, agitation and cavitation principle that can reach difficult inaccessible areas (almost 35\%) of the complex root canal system ${ }^{10}$

Literature had reported the efficiency of Passive ultrasonic irrigation (PUI) in removing debris, organic tissue and root canal dressing from in accessible are as in the root canal ${ }^{11}$. Grischke et al ${ }^{12}$ demonstrated the superiority of ultrasonic irrigation to other techniques during endodontic retreatment procedures in sealer removal from the root canal space.

Few studies had assessed the effectiveness of Endovac, UltraX and PUI on the removal of the gutta percha/bioceramic sealer during non-surgical endodontic retreatment. Thus, the purpose of this study was to assess and compare the effectiveness of conventional needle irrigation, Endovac, UltraX and PUI on the removal of residual obturation filling materials (Guttapercha/Bioceramic sealer) after using Protaper retreatment system.

The null hypothesis was that the different irrigation techniques would show no significant difference on the total area percentage of the residualroot canal filling materials.

\section{MATERIALS AND METHODS}

\section{Sample Size}

Based on Nguyen et al 13, a minimum total sample of 20 teeth was required to detect a significant difference between the four groups. The sample size was calculated using $\mathrm{G}$ Power software version 3.1.9.2.

\section{Selection and preparation of teeth}

This research was approved by the Research Ethics Committee (Number FUE.REC (10)/3-2020). Forty recently extracted single-rooted mandibular premolars due to prosthodontics or periodontal disease were collected from the department of oral 
and maxillofacial surgery clinic. Periodontal scaler was used to mechanically clean the root surface from soft tissues and calculus. Radiographs from different angulations (Buccolingual and Mesiodistal) were administered to ensure that the samples comprised mature apices with no calcification, root fracture, cracks and/or internal resorption. Preparation of the access cavities was completed using high-speed diamond burs and copious water coolant. For the working length (WL) determination, flattening of the crowns was performed to provide a reference point.

\section{Root canal preparation:}

The patency of the root canalswas checked by inserting a $15 \mathrm{~K}$-file (Mani, Japan) into the canals until it was noticeable at the apical foramen. Canals that did not permit the insertion of $15 \mathrm{~K}$-file to the apex or those with apex wider than $20 \mathrm{~K}$-file were excluded. The WL for canal preparation was created by subtracting one millimetre from the file length. Root canals were then prepared with Protaper Next NiTi rotary system (Dentsply, Maillefer) with the sequence SX $(19,0.04)$ to $1 / 2$ of the working length at a speed of $300 \mathrm{rpm}$ and torque of 3-4 Ncm. X1 (17, 0.04), X2 (25, 0.06), X3(30, 0.07) to the full WLat speed of $300 \mathrm{rpm}$ and torque of $2.5 \mathrm{Ncm}$. Protaper Next instruments were operated using the X-Smart Plus motor (Dentsply Maillefer, Baillagues, Switzerland)

Irrigation was done using $2 \mathrm{ml}$ of $2.6 \% \mathrm{NaOCl}$ between each file, then after completing the instrumentation procedures, $3 \mathrm{ml}$ of $17 \%$ ethylene diamine tetra acetic acid was applied for smear layer removal for 1 minute, followed by distilled water and then the canals were irrigated with $2 \mathrm{ml}$ of $2.6 \% \mathrm{NaOCl}$ followed by $10 \mathrm{ml}$ of distilled water as a final flush.

\section{Root canal obturation}

Canals were dried with paper points, and then obturated in lateral compaction technique using X3 guttapercha master cones coated with Sure Seal
(Sure Dent Corp., Gyeonggi-do, Korea). Roots were radiographed in multiple angulations (Buccolingual and mesiodistal)to verify the competency of obturation, the access cavity was sealed with Cavit (3M ESPE, St Paul, MN, USA). All the teeth were incubated at $37^{\circ} \mathrm{C}$ and $100 \%$ humidity for 4 weeks to ensure full setting of the sealer.

\section{Root canal retreatment}

Retreatment procedures were done using ProTaper Universal retreatment instruments (Dentsply Maillefer, Ballaigues, Switzerland) in a crown-down method. D1, D2, and D3 files were operated in a sequential order in a brushing action till reaching the WL. These files were connected to an electric motor (X-Smart Plus motor) which was operating at a speed of $500 \mathrm{rpm}$ for D1 and $400 \mathrm{rpm}$ for D2 and D3 and a torque of $3 \mathrm{~N} \mathrm{~cm}$. Adherent obturation material was removed from each file, before being reinserted in the root canal. After filing, the root canals were irrigated with $2.5 \mathrm{~mL}$ of $5.25 \% \mathrm{NaOCl}$. Each file was used in five canals only. Criteria for complete retreatment procedure; when the file reached the WL, remnants of the obturating material were not detected between the file flutes and clear irrigating solution.

The root apices were covered with wax to obtain a closed-end root canal and to avoid the irrigant overflow generating a vapour-lock effect. Roots were then, randomly divided into four groups $(n=10)$ according to the final irrigant activation protocol

\section{Conventional Irrigation group (CI)}

The canals were irrigated with a 30-gauge double side-vented needle (NaviTip, Ultradent, South Jordan, UT, USA), $15 \mathrm{~mL}$ of $5.25 \% \mathrm{NaOCl}$ for $3 \mathrm{~min}$ then distilled water and $5 \mathrm{~mL}$ of $17 \%$ EDTA for $1 \mathrm{~min}$. The needle was introduced to the root canal till reaching $2 \mathrm{~mm}$ of the working length without binding. The canals were flushed with $10 \mathrm{~mL}$ of distilled water. Then, canals were dried using paper points. 


\section{EndoVac system group: (EV)}

EndoVac system (Discus Dental, Culver City, USA) was used to irrigate the canals with $5.25 \%$ $\mathrm{NaOCl}$ using the delivery/evacuation tip over a 30-second. Then, the microcannula placed 2 $\mathrm{mm}$ short of the WL, aspirated the irrigant. The irrigant was left for 60 seconds in the canal. Then, the microcannula was introduced at the WL for 6 seconds, while the pulp chamber was full of irrigant. The microcannula was put $2 \mathrm{~mm}$ short of the WL for 6 seconds and then moved back for 6 seconds. This up and down motion remained for 30 seconds to ensure 18 seconds of active irrigation directly at the WL. Then, the microcannula was withdrawn and the canal was left for 60 seconds filled with irrigant. Distilled water was applied followed by irrigation with 17\% (EDTA) for 1 minute. Then, the canals were rinsed and dried, as in the previous group.

\section{UltraXgroup: (UX)}

Final rinse with $5.25 \% \mathrm{NaOCl}$ by side vented needle. Acivato tip was selected that fits passively when placed 2-3 $\mathrm{mm}$ short of WL. The irrigant was agitated for 30 seconds using short vertical strokes. Followed by replenishing the irrigant using suction to eliminate loose debris. This cycle was repeated 6 times followed application of 17\% (EDTA) for 1 minute. Then, the canals were rinsed and dried, as in the previous group.

\section{Passive ultrasonic irrigation group: (PUI)}

Final PUI was performed by activation of the irrigating solutions with anultrasonic tip of size 25 and 0.1 taper, attached to an Acteon Satelec P5 Booster, Satelec P5 Newtron XS LED Scaler, passively inserted $2 \mathrm{~mm}$ short of the WL into the root canals. The ultrasonic tip and irrigation were simultaneously initiated $(30 \mathrm{kHz})$, according to the manufacturer's instructions. The irrigant was ultrasonically operated in the root canals for 3 minutes; along with a continuous flow of $15 \mathrm{~mL}$ of $5.25 \% \mathrm{NaOCl}$ followed by distilled water then $5 \mathrm{~mL}$ of $17 \%$ EDTA for $1 \mathrm{~min}$. Finally, the canals were rinsed and dried as in previous groups.

\section{Assessment of the efficiency of the retreatment procedures:}

\section{Stereomicroscopic evaluation of root canal clean- liness:}

Longitudinalgroove was created in each rootin bucco-lingual direction using a diamond disc to a depth just before reaching the canal space. The roots were split into two halves using mallet and chisel. Each half was examined with a digital camera connected to the stereomicroscope (Olympus, SZX9, Tokyo, Japan) with $15 \times$ magnification and images were captured. The areas with remaining obturation material (guttapercha/bioceramicsealer) in each root canal third were identified, outlined and assessed by one blinded observer with no attempt to differentiate between guttapercha and bioceramic sealer remnants.

All images were analysed using Image-J software (Image-J v 1.44, U.S. National Institutes of Health, Bethesda, MD, USA.), to measure the area of the remaining obturation material in each third (coronal, middle and apical). The ratio of the area of the remaining filling in pixels/ the area of the canal segment in pixels were analysed and expressed as the percentage of the residual filling material in each canal segment.

\section{Statistical Analysis:}

Numerical data of the area percentage of the remaining filling material were presented as mean, standard deviation (SD) values. Data were investigated for normality using KolmogorovSmirnov and Shapiro-Wilk tests and presented parametric distribution. One-way ANOVA followed by Tukey's post hoc test was used for intergroup comparisons while One-way repeated measures ANOVA followed by comparison of main effects utilizing bonferroni correction was used for intra 
group comparisons within all tests. Statistical analysis was performed with IBM ${ }^{\circledR} \quad$ SPSS ${ }^{\circledR}$ Statistics Version 26 for Windows. The significance level was set at $\mathrm{P} \leq 0.05$.

\section{RESULTS}

Mean and standard deviation (SD) values for the area percentage of the remaining filling material in different groups are presented in Table (1), Figure (1).

Results showed a statistically significant difference between different groups $(\mathrm{P}<0.001)$ as regard the total area percentage of the remaining filling material. Conventional needle irrigation showed the highest value of the remaining filling material (18.77 \pm 8.74$)$, followed by UltraX $(8.97 \pm 3.82)$, then Endovac $(8.60 \pm 3.82)$, while PUI showed the lowest mean value (5.95 \pm 2.04$)$. Pairwise comparisons showed conventional needle irrigation to have significantly higher residual material value than canals cleaned with other systems $(\mathrm{P}<0.001)$. As regard the area percentage of the remaining filling material at different root canal levels. There was a significant difference between the different root levels for the conventional needle irrigation, UltraX, EndoVac groups $(\mathrm{P}=0.004,0.002$ and 0.001 respectively). The apical third showed the highest area percentage of the remaining filling material, followed by the middle then the coronal level.

Pairwise comparisons showed that the value found at the apical level to be significantly higher than that found at the coronal level for the conventional needle irrigation and UltraX groups $(p<0.001)$ and significantly higher than that found at middle and coronal levels for the Endovac group $(\mathrm{p}<0.001)$. While, Passive ultrasonic irrigation showed no significant difference between different root levels $(\mathrm{p}=0.053)$. Figures $(2-5)$

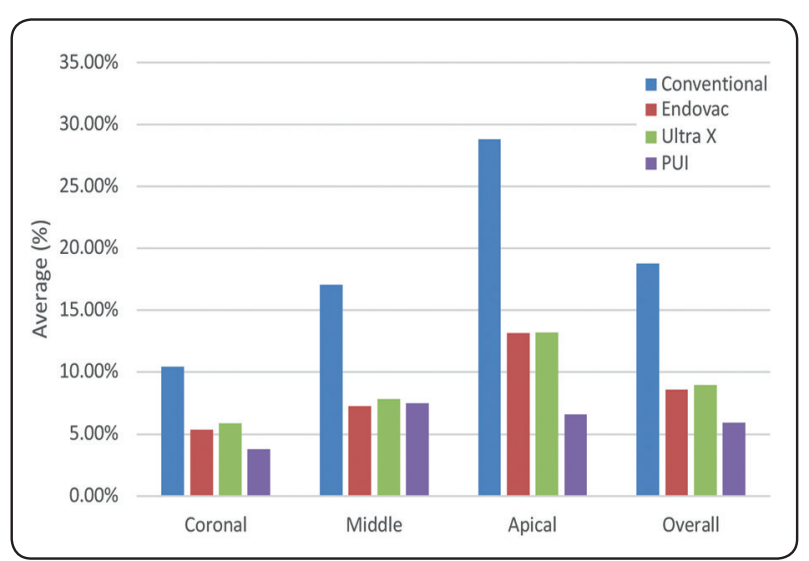

Fig. (1) Bar chart showing average area\% of filling material in different groups

TABLE (1): Mean and standard deviation (SD) values for area $\%$ of the remaining filling materials in different groups

\begin{tabular}{|c|c|c|c|c|c|}
\hline \multirow{2}{*}{ Root section } & \multicolumn{4}{|c|}{ Area \% (Mean \pm SD) } & \multirow{2}{*}{ p-value } \\
\cline { 2 - 5 } & Conventional & Endovac & Ultra X & PUI & \\
\hline Coronal & $10.45 \pm 3.27^{\mathrm{Ab}}$ & $5.36 \pm 0.87^{\mathrm{Bb}}$ & $5.89 \pm 1.08^{\mathrm{Bb}}$ & $3.79 \pm 0.25^{\mathrm{Ba}}$ & $0.001^{*}$ \\
\hline Middle & $17.07 \pm 4.27^{\mathrm{Aab}}$ & $7.28 \pm 2.29^{\mathrm{Bb}}$ & $7.83 \pm 2.48^{\mathrm{Bab}}$ & $7.48 \pm 1.72^{\mathrm{Ba}}$ & $0.001^{*}$ \\
\hline Apical & $28.79 \pm 4.64^{\mathrm{Aa}}$ & $13.17 \pm 1.80^{\mathrm{Ba}}$ & $13.19 \pm 2.84^{\mathrm{Ba}}$ & $6.58 \pm 1.57^{\mathrm{Ca}}$ & $<0.001^{*}$ \\
\hline Overall & $18.77 \pm 8.74^{\mathrm{A}}$ & $8.60 \pm 3.82^{\mathrm{B}}$ & $8.97 \pm 3.82^{\mathrm{B}}$ & $5.95 \pm 2.04^{\mathrm{B}}$ & $<0.001^{*}$ \\
\hline
\end{tabular}

Different upper and lowercase superscript letters indicate a statistically significant difference within the same horizontal row and vertical column respectively*; significant $(p \leq 0.05) n s$; non-significant $(p>0.05)$ 


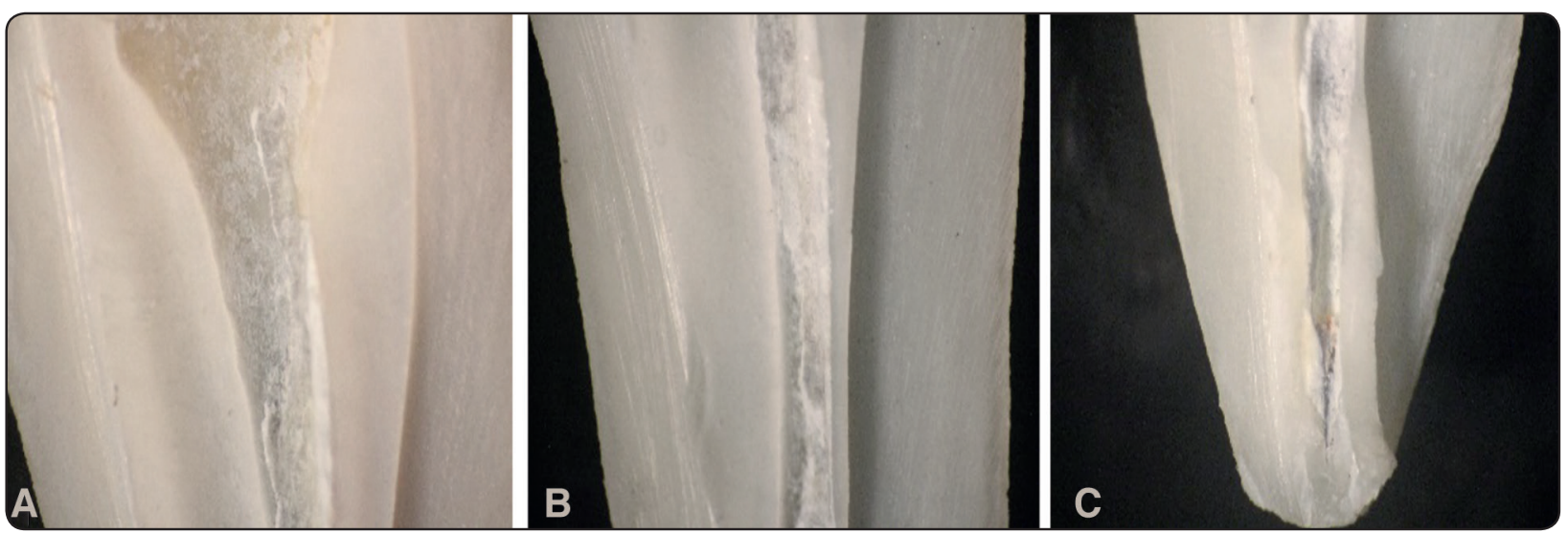

Fig. (2): Stereomicroscopy of a specimen after retreatment usingProTaper Universal retreatment system and conventional irrigation as a final irrigation protocol. (a) Coronal third $\quad$ (b) Middle third $\quad$ (c) Apical third

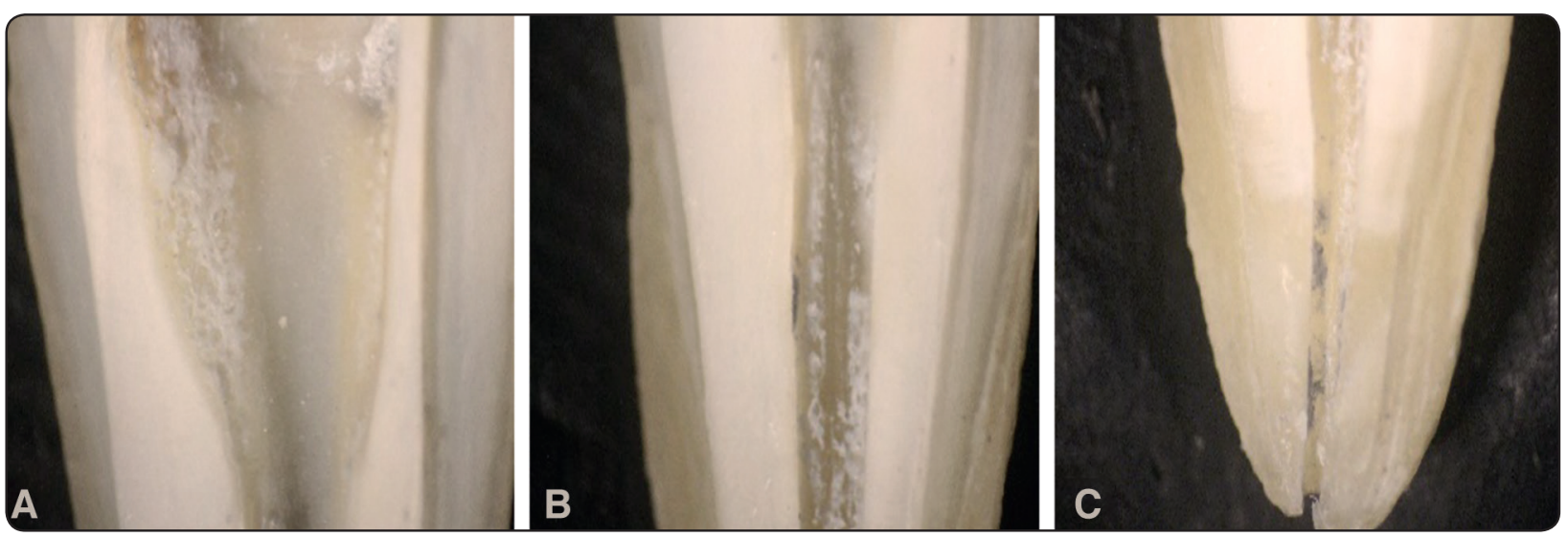

Fig. (3): Stereomicroscopy of a specimen after retreatment using ProTaper Universal retreatment system and EndoVac as a final irrigation protocol

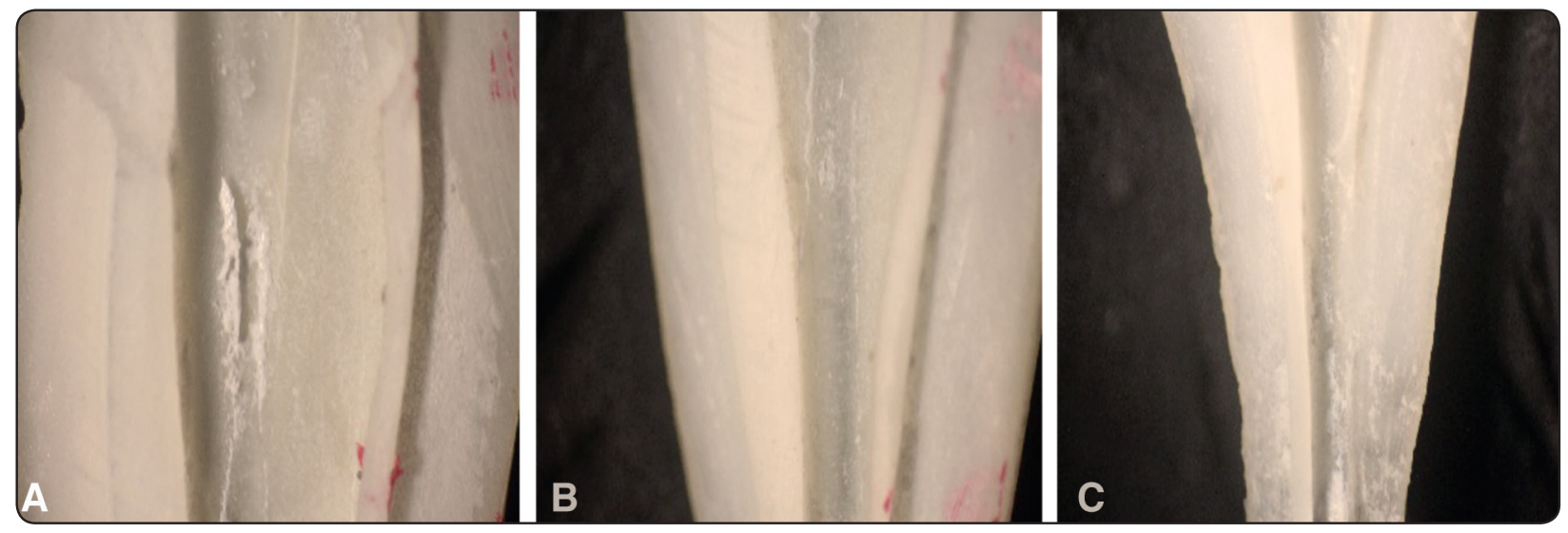

Fig. (4): Stereomicroscopy of a specimen after retreatment using ProTaper Universal retreatment system and Ulra X as a final irrigation protocol

(a) Coronal third (b) Middle third (c) Apical third 


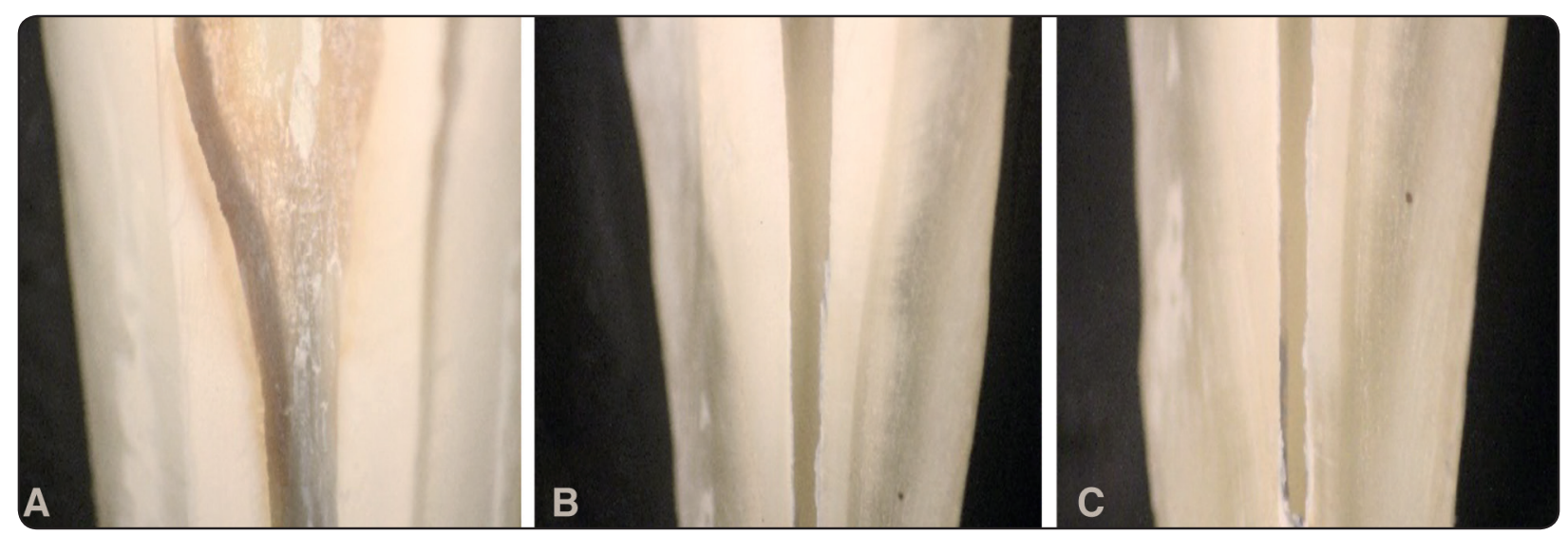

Fig. (5): Stereomicroscopy of a specimen after retreatment using ProTaperUniversal retreatment system and passive ultrasonic irrigation as a final irrigation protocol (a) Coronal third $\quad$ (b) Middle third $\quad$ (c) Apical third

\section{DISCUSSION}

A great attention has been drawn toward nonsurgical endodontic retreatment, due to the increased demand to preserve teeth with failed endodontic therapy ${ }^{14}$. The retreatment success depends on complete removal of the obturation materials which has shown to be challenging ${ }^{7,15}$. Not only the removal of filling material from the canal can expose necrotic tissues and/or bacteria which are responsible for periapical inflammation, but also it allows for further disinfection and instrumentation of the canal ${ }^{16}$. The ability to achieve patent canal and to clean its apical part has been recognized as the prognostic factors associated with the periapical healing.

Several instruments have been proposed for guttapercha removal, however, rotary instruments have been recommended for their high efficiency, speed and safety ${ }^{15}$. However, Gu et al. ${ }^{17}$ stated that retreatment with rotary instruments left about $10.0 \%$ to $17.0 \%$ of the surface of the canals covered by residual obturation materials. Irrigation has been proven to be mandatory during the primary root canal treatment procedures and non-surgical retreatment cases as it allows for additional canal debridement beyond that accomplished by root canal instrumentation ${ }^{18}$. In this study, different irrigation protocols were applied after rotary instrumentation to examine their efficiency in the removal of residual obturation materials (Guttapercha/ Bioceramic sealer).

Root canals have variable cross-section and morphology, making it difficult to clean and have a great impact on the alterations that may appear after canal preparation and after retreatment. Thus, mandibular premolars with single canals were selected to minimize these changes that may influence the results ${ }^{19}$. ProTaper Universal retreatment instruments were utilized for their good performance which is attributed to their design features. The system comprises 3 instruments: D1, D2 and D3 which show progressive lengths and tapers, enabling them to cut the guttapercha and the superficial dentine layer during the removal of obturation materials. Furthermore, the flute design as well as the rotary motion of the ProTaper Universal retreatment system tends to pull the guttaperchatowards the file flutes and guide it towards the orifice of the canal. Moreover, the rotary motion produces frictional heat which plasticizes the guttapercha, rendering it less resistant and easier to remove ${ }^{20}$.

In this study, $2.6 \% \mathrm{NaOCl}$ was used as a routine irrigation during cleaning and shaping procedures because of its broad antibacterial effect and organic material dissolution ability. Unlike, the 
high concentration of $\mathrm{NaOCl}$ (5.25\%) which is highly toxic, cause degradation of the dentin matrix components thereby affecting the mechanical properties of the teeth. Since $\mathrm{NaOCl}$ lacks the ability to dissolve inorganic material, the smear layer was removed by using $3 \mathrm{ml}$ of $17 \%$ EDTA, then $10 \mathrm{ml}$ distilled water was used immediately after EDTA to avoid the prolonged effect of the chelating agent on the root dentine microhardness ${ }^{21}$.

Different practises have been employed to assess the amount of the residual obturation material after the retreatment procedures as clearing methods, radiography, cone beam computed topography, scanning electron microscope and stereomicro scope 22, 23. Our specimens were longitudinally split, and the percentage of the residual obturation material was determined from images captured under stereomicroscope. This method is considered more reliable than radiographic evaluation which only provides a 2-dimensional view. Also, this method can determine the amount of the remaining filling material, and minimize the subjectivity associated with the scale-based scoring method ${ }^{24}$. Recently, micro-CT has shown efficacy in assessing the retreatment techniques in three dimensions without specimen destruction (8). However, there is a limited access to the device.

Results showed that the lowest statistically significant area percentage of the remaining obturation material was associated with the usage of PUI. PUI allows the tip to freely move inside the canal which is essential for easy irrigant penetration and provides a strong cleaning effect ${ }^{25}$. During PUI, the energy is conveyed through ultrasonic waves from the file to the irrigant produce two physical phenomena: Acoustic streamand irrigant cavitation. The acoustic stream is the rapid fluid movement in circular or vortex shape around the file, while cavitation is the distortion of the existing bubbles in the irrigant ${ }^{26}$. Additionally, PUI retreatment removes sealer and guttapercha debris from areas that are inaccessible to conventional retreatment files. This could be attributed to guttapercha plasticizationcaused by tip vibrationthat causes sealer de-bonding and the heatgenerated by the tip friction ${ }^{27}$.

Results were in approval with Bernardes et $\mathrm{al}^{28}$ and Capar et al. ${ }^{29}$ who demonstrated that using PUI during root canal retreatment enhances the obturation material removal by producing cleaner canal surfaces than passive sonic irrigation. Also, Bedier et al 30 demonstrated the superiority of PUI in retreatment procedures.

Our results showed that conventional needle irrigation showed the highest value of the remaining filling material (18.77 \pm 8.74$)$, followed by UltraX $(8.97 \pm 3.82)$, then Endovac $(8.60 \pm 3.82)(\mathrm{P}<0.001)$.

The EndoVac system aspirates the irrigant in a fast way, producing an air induction system and twophase fluid flow dynamics 31. Additionally, using micro/macro cannulas produces vacuum inside the canal, creates a pressure difference and supplies a non-stop irrigant flow to the WL ${ }^{32-34}$. Moreover, the negative pressure irrigation created apically enhances continuous replacement of the irrigant inside the root canal ${ }^{35}$. The EndoVac system was presented to solve the problems of air entrapment and irrigant flushing at the apex ${ }^{36}$.

Studies have confirmed a direct relationship between enlarged apical size preparations, increased instruments taper with the improved efficiency of the instruments ${ }^{37}$ and enhanced debridement $1 \mathrm{~mm}$ from the WL for the EndoVac system compared with conventional needle irrigation. On the contrary, Wright et al ${ }^{38}$ showed the ability of EndoVacin the removal of $9 \%$ of the residual obturation material, while the side-vented needle group removed about $16 \%$. This difference could be attributed to the mechanical syringe agitation in a 3-4 $\mathrm{mm}$ up and down motion. They showed that both EndoVac (pure irrigation) and Gentle Wave (multi sonic energy) were less effective in the removal of obturation debris than side-vented needle (mechanical energy).

Though, other studies had revealed that the EndoVac provided a significant debris removal at the apical part of the root canal ${ }^{39,40}$. Though, these 
studies haven't inspected the canal cleanliness and debris removal during nonsurgical retreatment.

On the other hand, UltraX is mainly based upon ultrasonic technology. The reason for less efficiency of UltraX could be explained as UltraX creates acoustic micro-streaming generating shear stresses for dislodging debris from instrumented canals. It possesses multiple nodes and antinodes through the length of the activated ultrasonic file, however undesirable dampening effect of its characteristic nodes and antinodes pattern occurs when the instrument comes in contact with the lateral walls of the shaped canals. It can be postulated that the ultrasonic energy may be reduced and absorbed in the presence of visco-elastic materials causing its reduced effectiveness ${ }^{41}$.

The apical third showed the highest area percentage of the remaining filling material, followed by the middle then the coronal level. As regard the root level, the apical third showed the highest statistically significant area percentage of the remaining filling material, followed by the middle then the coronal levelfor the conventional needle irrigation, UltraX and EndoVac groups $(\mathrm{P}=0.004,0.002$ and 0.001 respectively).

The worst cleaning for all the studied techniques except for the PUI was achieved in the apical part. Some studies have presented similar results ${ }^{42,43}$ though other studies showed controversial results ${ }^{44,45}$. All of the retreatment techniques showed the finest results in the middle part of the root canal. Where, this area shows a simpler root canal anatomy that is not complicated as the apical or the coronal parts, smooth walls, and the sealer is easier to be removed.

UltraX, EndoVac and conventional needle irrigation groups showed a significant difference between the different root levels. Our study is consistent with Schoeffel study ${ }^{36}$, EndoVac system showed lower scores at the apical third when compared with the middle and coronal thirds. The UltraX (Ultrasonically activated) is associated with apical penetration of the irrrigant solution ${ }^{46}$. However, their insufficient activity, particularly at the apical part of the root, can be justified by the use of low-power devices and subsequent absence of produced cavitation effects. Jiang et al. ${ }^{46}$ stated that the enhanced canal cleanliness associated with ultrasonic activation is attributed to the energy level. In our study, though UltraX was moderately adequate for cleaning the coronal and middle levels, it was considered inadequate at the apical level.

The use of PUI presented no significant difference between different root levels because of the direction of operation and the use of straight root canals ${ }^{47}$. It is crucial to allow the file to freely move within the root canal space, to allow easy penetration of the irrigant, thus enhancing the cleaning efficacy 25 . This effect would be reduced in curved canals due to limited tip movement through the curvature, causing limited cleaning at the apical part ${ }^{13}$.

\section{CONCLUSION}

Within the parameters of this study, none of the assessed irrigation protocols was capable of entirely removing the residual obturation material from the root canal system. PUI showed higher potentiality in removing additional residual obturation material (Guttapercha/bioceramic sealer) than the UltraX and EndoVac groups.

\section{REFERENCES}

1. Rios MA, Villela AM, Cunh a RS, et al. Efficacy of 2 reciprocating systems compared with a rotary retreatment system for guttapercha removal. J Endod., 40:543-6, 2014.

2. Hargreaves K, Berman L. Cohen's Pathways of the Pulp Expert Consult. 10th Edition. Part 1: The Core Science of Endodontics. Mosby., 2010.

3. Al Haddad A, Che Ab Aziz ZA. Bioceramic-Based Root Canal Sealers: A Review. Int J Biomater., May;9753210, 2016.

4. Kossev D, Stefanov V. Ceramics-based sealers as new alternative to currently used endodontic sealers. Roots., 1:42-48, 2009. 
5. Kasam S, Mariswamy AB. Efficacy of different methods for removing root canal filling material in retreatment-an in-vitro study. J Clin Diagn Res., 10: 6-10., 2016.

6. Özyürek T, Demiryürek EÖ. Efficacy of different nickeltitanium instruments in removing guttapercha during root canal retreatment. J Endod., 42:646-9, 2016.

7. Zuolo AS, Mello JE, Cunha RS, et al. Efficacy of reciprocating and rotary techniques for removing filling material during root canal retreatment. . Int Endod J., 46: 947-53, 2013.

8. Barletta FB, Rahde NM, Limongi O, et al. In vitro comparative analysis of 2 mechanical techniques for removing guttapercha during retreatment. J Can Dent Assoc., 73:65, 2007.

9. Miller TA, Baumgartner JC. Comparison of the Antimicrobial Efficacy of Irrigation Using the EndoVac to Endodontic Needle Delivery. J Endod., 36:509-511, 2010.

10. Choudhary A, Farooq R, Purra AR, et al. Ultrasonic versus sonic activation of the final irrigant in root canals instrumented with rotary files: An in-vitro stereomicroscopic analysis. International Journal of Research and Review.,6:22-26, 2019.

11. VanderSluis LW, Wu MK,Wesselink PR. The evaluation of removal of calcium hydroxid epastefroman artificial standardized groove in the apical root canal using different irrigation methodologies. Int. Endod. J., 40:52-57, 2007.

12. Grischke, J, Muller-Heine A, Hulsmann M. The effect of four different irrigation systems in the removal of a root canal sealer. Clin. Oral Investig., 18: 1845-1851, 2014.

13. Nguyen TA, Kim Y, Kim E, et al. Comparison of the efficacy of different techniques for the removal of root canal filling material in artificial teeth: A Micro-Computed Tomography Study.J. Clin. Med., 8:984, 2019.

14. Lovdahl PE. Endodontic retreatment. Dent Clin North Am., 36:473-90, 1992.

15. Gergi R, Sabbagh C. Effectiveness of two nickel-titanium rotary instruments and a hand file for removing guttapercha in severely curved root canals during retreatment: an ex vivo study. Int Endod J., 40:532-7, 2007.

16. Friedman S, Stabholz A, Tamse A. Endodontic retreatmentcase selection and technique. Part 3. Retreatment Techniques. J Endod., 16:543-9, 1990.

17. Gu LS, Ling JQ, Wei X, et al. Efficacy of ProTaper Universal rotary retreatment system for guttapercha removal from root canals. Int Endod J., 41: 288-295, 2008.
18. Celik GU, UreyenKaya B, Tac AG, et al. A comparison of the efficacy of conventional and newretreatment instruments to remove guttapercha in curved root canals: an ex vivo study. Int Endod J., 42: 344-350, 2009.

19. Moushmi CB, Abhinav D, Deepak CC. Efficacy of two rotary retreatment systems in removing guttapercha and sealer during endodontic retreatment with or without solvent: A comparative in vitro study. J Conserv Dent., 20: 12-16, 2017.

20. Betti LV, Bramante CM.Quantec SC rotary instruments versus hand files for guttapercha removal in root canal retreatment. Int Endod J.,34: 514-9, 2001.

21. Chang YC1, Huang FM, Tai KW, et al. The effect of sodium hypochlorite and chlorohexidine on cultured human periodontal ligament cells. Oral Surg Oral Med Oral Pathol Oral RadiolEndod., 92: 446-450, 2001.

22. Unal GC, Kaya BU, Tac AG, et al. A comparison of the efficacy of conventional and new retreatment instruments to remove guttapercha in curved root canals: an ex vivo study. Int Endod J., 42: 344-350, 2009.

23. Oltra E, Cox TC, LaCourse MR, et al.Retreatability of two endodontic sealers, EndoSequence BC Sealer and AH Plus: a micro- computed tomographic comparison. Restor Dent Endod., 42:19-26, 2017.

24. Saad AY, Al-Hadlaq SM, Al-Katheeri NH. Efficacy of two rotary NiTi instruments in the removal of guttapercha during root canal retreatment. J Endod., 33:38-41, 2007.

25. Merino A, Estevez R, de Gregorio C, et al. The effect of different taper preparations on the ability of sonic and passive ultrasonic irrigation to reach the working length in curved canals. Int Endod J., 46:427-33, 2013.

26. Mozo, S.; Llena, C.; Forner, L. Review of ultrasonic irrigation in endodontics: Increasing action of irrigating solutions. Med. Oral Patol. Oral Cir. Bucal., 17: 512-516, 2012.

27. Rached-Junior FA, Sousa-Neto MD, Bruniera JF, et al. Confocal microscopy assessment of filling material remaining on root canal walls after retreatment. Int Endod J., 47:264-70, 2014

28. Bernardes RA, Duarte MAH, Vivan RR, et al. Comparison of three retreatment techniques with ultrasonic activation in flattened canals using micro-computed tomography and scanning electron microscopy. Int Endod J., 49: 890-897, 2016.

29. Çapar ID, Ari Aydinbelge H. Effectiveness of various irrigation activation protocols and the self adjusting file system on smear layer and debris removal. Scanning., 36:640-7, 2014. 
30. Bedier MM and Roshdy NN. Efficiency of passive ultrasonic irrigation in removal of root canal filling material using R-Endo and D-RaCe retreatment systems. ENDO (LondEngl)., 12:101-108, 2018.

31. Goode N, Khan S, Eid AA, et al. Wall shear stress effects of different endodontic irrigation techniques and systems. J Dent., 41:636-41, 2013.

32. Shin SJ, Kim HK, Jung IY, et al. Comparison of the cleaning efficacy of a new apical negative pressure irrigating system with conventional irrigation needles in the root canal. Oral Surg Oral Med Oral Pathol Oral RadiolEndod., 109:479-84, 2010.

33. Susin L, Liu Y, Yoon JC, et al. Canal and isthmus debridement efficacies of two irrigant agitation techniques in a closed system. Int Endod J., 43:1077-90, 2010.

34. Gu LS, Kim JR, Ling J, et al. Review of contemporary irrigant agitation techniques and devices. J Endod., 35:791-804, 2009.

35. Ribeiro EM, Silva-Sousa YT, Souza-Gabriel EA, et al. Debris and smear removal in flattened root canals after use of different irrigantagitation protocols. Microsc Res Tech., 75:781-90, 2012.

36. Schoeffel GJ. The EndoVac method of endodontic irrigation, part 2-efficacy. Dent Today., 27: 82-87, 2008.

37. Usman N, Baumgartner JC, Marshall JG. Influence of instrument size on root canal debridement. J Endod., 30:110-2, 2004.

38. Wright CR, Glickman GN, Jalali P, et al.Effectiveness of guttapercha/Sealer removal during retreatment of extracted human molarsusing the gentlewave system. J Endod., 45:808-812, 2019.
39. Nielsen BA, Baumgartner JC. Comparison of the EndoVac system to needle irrigationof root canals. J Endod., 33:611-5, 2007.

40. Siu C, Baumgartner JC. Comparison of the debridement efficacy of the EndoVacirrigationsystem and conventional needle root canal irrigation in vivo. J Endod., 36:1782-5, 2010.

41. Krautkramer J, Krautkramer H. Ultrasonic testing of materials. Berlin, Heidelberg:Springer-Verlag; 1977.

42. Ersev H, Yilmaz B, Dincol ME,et al. The efficacy of Pro Taper Universal rotary retreatment instrumentation to remove single guttapercha cones cemented with several endodontic sealers. Int Endod J., 45:756-62, 2012.

43. Siotia J, Acharya SR, Gupta SK. Efficacy of ProTaper retreatment system in root canals obturated with guttapercha using two different sealers and guttaflow. Int J Dent., 676128, 2011.

44. Uzunoglu E, Yilmaz Z, Sungur D, et la. Retreatabilityof root canals obturated using guttapercha with bioceramic, MTA and resin-basedsealers. Iran Endod J., 10:93-8, 2015.

45. Madani ZS, Simdar N, Moudi E, et al. CBCT Evaluation of the root canal filling removal using DRaCe, ProTaper retreatment kit and hand files in curved canals. Iran Endod J., 10:69-75, 2015.

46. Jiang LM, Verhaagen B, Versluis M, et al. The influence of the ultrasonic intensity on the cleaning efficacy of passive ultrasonic irrigation. J Endod., 37: 688-92, 2011.

47. Weller RN, Brady JM, Bernier WE. Efficacy of ultrasonic cleaning. J. Endod., 6: 740-743, 1980. 